\title{
PROSES PENGAJUAN ANGGARAN OLEH DINAS KESEHATAN KABUPATEN BULELENG DALAM MENUNUJANG MASYARAKAT TIDAK MAMPU YANG BELUM MEMILIKI KARTU INDONESIA SEHAT
} (KIS)

\author{
I Ketut Deita Candra Prayoga, Komang Ryan Krisna Satriadi, Ni Putu Ayu \\ Amanda Putri, Gst. Km. Angtri Ananta Wijayanana, I Putu Wahyu Aditya Putra \\ Jurusan Akuntansi, Universitas Pendidikan Ganesha, Singaraja, Buleleng, Bali
}

\begin{abstract}
Abstrak
Penelitian ini bertujuan untuk menginvestigasi adanya potensi penyimpangan pada organisasi pemerintahan. Investigasi dilakukan dengan menggunakan pendekatan Fraud Triangle pada dinasdinas di Kabupaten Buleleng-Bali. Pengumpulan data dilakukan melalui metode wawancara dan dokumentasi. Hasil penelitian menunjukkan bahwa terdapat potensi kecurangan pengelolaan keuangan akibat kurangnya pengawasan yang dilakukan. Dalam kaitannya dengan Fraud Triangle, inin berhubungan dengan aspek opportunity (kesempatan) yang memungkinkan tindakan kecurangan dapat terjadi.
\end{abstract}

Kata kunci: Fraud triangle; organisasi pemerintahan; Buleleng

\section{Abstract}

This study aims to investigate the potential for irregularities in government organizations. Investigations were carried out using the Fraud Triangle approach in agencies in the Regency of Buleleng, Bali. Data collection is done through interviews and documentation. The results showed that there was potential for financial management fraud due to lack of supervision conducted. In connection with the Fraud Triangle, this is related to the opportunity aspect (opportunity) that allows fraud to occur.

Keywords: Fraud triangle; government organization; Buleleng

\section{Pendahuluan}

Undang-Undang Dasar Republik Indonesia tahun 1945 telah mengamanatkan, setiap warga negara berhak atas jaminan sosial untuk dapat memenuhi kebutuhan dasar hidup yang layak dan meningkatkan martabatnya menuju terwujudnya masyarakat Indonesia yang sejahtera, adil, dan makmur. Untuk itulah, melalui Undang-Undang Nomor 40 Tahun Tahun 2004, dibentuklah Sistem Jaminan Sosial Nasional. Sistem merupakan program negara yang bertujuanmemberikan kepastian perlindungan dan kesejahteraan sosial bagi seluruh rakyat.

KIS adalah program yang dikeluarkan oleh presiden Joko Widodo dan wakil presiden Jusuf Kalla untuk membuat rakyat lebih sehat dan sejahtera. Berselang 14 hari setelah dilantik sebagai Presiden RI ke-7, Joko Widodo resmi meluncurkan KIS bersamaan juga dengan KIP (Kartu Indonesia Pintar) dan KKS (Kartu Keluarga Sejahtera).Kartu Indonesia Sehat (KIS) sendiri adalah kartu yang memiliki fungsi untuk memberikan jaminan kesehatan kepada masyarakat untuk mendapatkan pelayanan kesehatan secara gratis. Dengan adanya KIS ini harapannya antara Kementerian Kesehatan, Kementerian Sosial, Dewan Jaminan Sosial Nasional, Pemerintah Daerah dan BPJS Kesehatan berjalan sesuai bidang dan tugasnya. Penggunanya sendiri dapat menggunakan fungsi KIS ini di setiap fasilitas kesehatan tingkat pertama dan tingkat lanjut. Kartu ini sendiri merupakan program yang bertujuan untuk melakukan perluasan dari program kesehatan yang sebelumnya yaitu BPJS Kesehatan yang telah diluncurkan oleh mantan presiden SBY (Susilo Bambang Yudhoyono) pada tanggal 1 Maret 2014 kemarin.

Pelaksanaan Kartu Indonesia Sehat (KIS) merupakan bagian dari upaya pemerintah dalam memberikan pelayanan kesehatan secara menyeluruh bagi masyarakat yang masuk dalam kategori fakir miskin dan orang tidak mampu. Sasaran KIS adalah mereka yang 
tergolong dalam dua kategori tersebut, hal ini dikarenakan angka kemiskinan di negara ini yang masih sulit ditekan. Haughton (2012:3) menyatakan bahwa kemiskinan timbul akibat masyarakat tidak memiliki kemampuan-kemampuan utama, tidak memiliki pendapatan atau mendapatkan pendidikan yang memadai, memiliki kondisi kesehatan yang buruk, merasa tidak aman, memiliki kepercayaan kepercayaan diri yang rendah. KIS sudah dimulai pada tahun 2015 di Kabupaten Buleleng dan merupakan kartu yang diberikan oleh pemerintah sebagai jaminan sosial dan kesehatan agar masyarakat dapat berobat secara gratis di fasilitas kesehatan yang telah ditentukan.

Pada tahun 2017 realisasi penerima KIS bagi masyarakat kurang mampu di Kabupaten Buleleng masih belum merata. Terdata semula ada 256.334 jiwa warga Buleleng kurang mampu mendapat pelayanan KIS dengan sumber dana dari APBN. Meski demikian, masih ada 117.439 jiwa yang tercecer, kemudian dilayani KIS PBI dengan tanggungan daerah melalui sharing APBD Provinsi dan Kabupaten. Kendati yang tercecer itu sudah tertanggani, ternyata masih ada yang belum terlayani. Akhirnya Pemkab Buleleng mengusulkan pada Pemprov Bali tambahan kuota layanan KIS PBI. Hasilnya, disepakati tambahan kuota itu 30 persen atau 35.321 jiwa, dengan kebutuhan dana Rp 9,5 miliar setahun. Dimana komposisinya APBD Provinsi Bali Rp 5 miliar, sisanya Rp 4,5 miliar ditanggung APBD Buleleng.

Persoalan yang muncul saat ini adalah Pemkab Buleleng melalui Dinas Kesehatan tidak mengaalokasikan tambahan dana sharing Rp 4,5 miliar itu pada APBD Induk 2018. Ini diketahui setelah dalam daftar isian pelaksanaan anggaran (DIPA) di Dinas Kesehatan, tidak tercantum tambahan dana tersebut. Sedangkan Pemprov Bali sudah menyiapkan dana sebesar Rp 5 miliar, bahkan sudah siap ditransfer. Karena kegiatan itu tidak ada dalam DIPA, sehingga dana provinsi tidak bisa dimanfaatkan. Sedangkan warga miskin dalam tambahan kuota 35.321 jiwa sudah ada yang berobat ke rumah sakit. "Tentu ini sangat kami sayangkan, karena tambahan kuota itu sudah kami sosialisasikan ke masyarakat. Dimana tidak ada lagi persoalam KIS PBI, karena semua masyarakat yang terecer sudah bisa terlayani KIS. Tetapi sekarang ada persoalan masalah anggarannya," kata Ketua Komisi IV DPRD Buleleng, Gede Wisnaya Wisna.

Berdasarkan batasan masalah yang telah ditentukan diatas, maka peneliti merumuskan beberapa masalah yang nantinya akan diteliti. Adapun rumusan masalah tersebut sebagai berikut: 1. Bagaimana proses pengajuan anggaran oleh Dinas Kesehatan Kabupaten Buleleng dalam mengalokasikan dana khususnya untuk masyarakat yang belum mendapatkan KIS? 2. Mengapa Pemkab Buleleng melalui Dinas Kesehatan tidak mengalokasikan tambahan dana sharing pada DIPA (Daftar Isian Pelaksanaan Anggaran) sebesar 4,5 miliar pada APBD induk 2018? 3. Bagaimana dampak terhadap masyarakat dari anggaran yang tidak terealisasi tersebut? 4. Jika dana yang dialokasikan oleh Dinas Kesehatan Kabupaten Buleleng sudah terdapat dalam DIPA dan sudah terealisasi sesuai dengan APBD yang diajukan, apa langkah atau kebijakan selanjutnya?

\section{Hasil dan Pembahasan}

\subsection{Gambaran Umum Organisasi}

\section{Fungsi, Tugas, dan Struktur}

Berdasarkan Peraturan Bupati Buleleng Nomor 75 tahun 2016 tentang Tugas Pokok dan Fungsi Perangkat Daerah Kabupaten Buleleng, Dinas Kesehatan Kabupaten Buleleng mempunyai tugas pokok melaksanakan kewenangan otonomi daerah di bidang kesehatan. Adapun fungsinya adalah perumusan kebijakan teknis di bidang kesehatan, menyelenggarakan urusan pemerintahan dan pelayanan umum di bidang kesehatan,Pelaksanaan Upaya Kesehatan yang meliputi peningkatan derajat (promotif) pencegahan (preventif), pengobatan (kuratif), dan pemulihan (rehabilitatif) di bidang kesehatan, pelaksanaan pemberian ijin di bidang kesehatan sesuai dengan kewenangan dan kebijakan yang ditetapkan oleh Bupati serta peraturan perundang-undangan yang berlaku, pembinaan upaya kesehatan dasar, kesehatan keluarga, promosi kesehatan, serta pengendalian penyakit menular, pembinaan terhadap Unit Pelaksana Teknis Dinas, beserta jaringan dan sarana pelayanan kesehatan swasta di bidang kesehatan, pengelolaan tata 
usaha dinas. Dinas Kesehatan Kabupaten Buleleng mempunyai struktur organisasi pada bagan

\section{1). Visi Dinas Kesehatan}

Visi Dinas Kesehatan Kabupaten Buleleng adalah MASYARAKAT SEHAT MANDIRI MENUJU BULELENG SEJAHTERA BERLANDASKAN TRI HITA KARANA .

Makna utama dari Visi Pembangunan Dinas Kesehatan Kabupaten Buleleng:

- $\quad$ Masyarakat Buleleng Sehat : Masyarakat Buleleng dengan Keadaan Sehat baik secara fisik, mental, spiritual mauapun sosial yang memungkinkan setiap orang untuk hidup produktif secara sosial dan ekonomi"

- Masyarakat Buleleng Yang Mandiri : Meningkatnya partisipasi/swadaya masyarakat dalam memenuhi sendiri kebutuhan akan kesehatan, sehingga dapat menolong dirinya sendiri di bidang kesehatan.

- $\quad$ Masyarakat BulelengYang Sejahtera : Merupakan suatu kondisi masyarakat yang mampu memenuhi kebutuhan hidupnya, baik lahir maupun batin secara adil, merata, rukun, damai, toleransi, berdisiplin, kreatif, produktif dan professional.

\section{2). Misi Dinas Kesehatan}

Misi organisasi merupakan pernyataan mengenai hal-hal yang harus dicapai organisasi di masa mendatang oleh semua pihak yang berkepentingan untuk mencapai Visi organisasi. Untuk mencapai Visi tersebut, maka Misi Dinas kesehatan Kab. Buileleng dapat dirumuskan sebagai berikut :

$1 \quad$ Menikngkatkan Derajat Kesehatan Masyarakat

2 Meningkatkan Aksisibilitas Pelayanan Kesehatan

3 Meningkatkan kemandirian masyarakat dalam bidang kesehatan

$4 \quad$ Meningkatkan Manajemen dan Informasi Kesehatan

$5 \quad$ Menciptakan Tata Kelola Pemerintahan Yang Baik

\section{3). Program Unggulan Dinas Kesehatan Kabupaten Buleleng}

Dinas Kesehatan Kabupaten Buleleng mempunyai Program Unggulan antara lain :

\section{Sanitasi Total Berbasis Masyarakat (STBM)}

Kegiatan yang direncanakan oleh masyarakat untuk memperbaiki masalah kesehatan lingkungna di desanya melalui 5 pilar STBM yaitu 1.Stop BAB sembarangan, 2. Cuci Tangan Pakai Sabun, 3.Pengelolaan Air dan Makanan Rumah Tangga, 4.Pengelolaan Sampah Rumah Tangga, Pengelolaan limbah cair Rumah Tangga)

\section{Kabupaten Sehat}

Kegiatan yang terintegrasi dengan sektor terkait yang pelaksanaannya minimal 2 tatanan (kehidupan masyarakat sehat dan mandiri, dan pemukiman serta sarana dan prasaran umum)

\section{$3 \quad$ Immunisasi}

Pemberian immunisasi kepada balita untuk mencegah terjadinya kelainan maupun gangguan kesehatan lainnya.

\section{$4 \quad$ Buleleng Emergency Service (BES)}

Upaya memberikan pelayanan Sistem penanggulangan gawat darurat terpadu dengan menyediakan satu pusat layanan informasi cepat (Hotline Service Center 233333) dan tenaga terlatih dalam penanggulangan penderita gawat darurat, serta menhyediakan pos gawat darurat terpadu (Public Safety Center).

\section{$5 \quad$ Pemeriksaan IVA Cryo} asetat.

IVA- Cryo atau deteksi dini kanker serviks melalui tes inspeksi visual dengan asam

\section{$6 \quad$ Penanggulangan Kasus Gizi Buruk Melalui :}

Pemberian PMT pemulihan: Pemberian Makanan Tambahan kepada penderita Gizi Buruk dengan tujuan untuk meningkatkan status gizi penderita tersebut 
Pemantauan pertumbuhan (posyandu): Dilakukan pemantauan berupa pengukuran lingkar lengan atas, lingkar kepala, maupun berat badan untuk menegetahui secara dini gejala terjadinya kasus Gizi Buruk

Pemberian Taburia: Pemberian Mineral dan vitamin kepada penderita Gizi

Buruk

Konseling / Penyuluhan: Penyebarluasan informasi baik secara personal maupun forum untuk mencegah dan menangani terjadinya kasus gizi buruk.

\subsection{Proses Pengajuan Anggaran Oleh Dinas Kesehatan Kabupaten Buleleng}

Anggran Pendapatan Daerah (APBD) merupakan anggaran daerah yang berisi tentang rencana kegiatan yang dipresentasikan dalam bentuk rencana perolehan pendapatan dan belanja dalam suatu lingkup daerah atau dapat dikatankan sebagai rencana keuangan tahunan daerah di Indonesia yang disetujui oleh dewan perwakilan rakyat daerah. Dimana APBD ditetapkan dengan Peraturan Daerah. Dalam bentuk yang paling sederhna yang menggambarkan kondisi keuangan dari suatu organisasi yang meliputi informasi mengenai pendapatan, belanja, dan aktivitas. Anggaran Berisi estimasi mengenai apa yang dilakukan organisasi di masa yang akan datang. Setiap anggaran memberikan informasi mengenai apa yang hendak dilakukan dalam beberapa periode yang akan datang.

Didalam proses penganggaran KIS yang dilakuakan yang dimana memiliki kasus mengenai anggaran yang tidak terealisasi sebesar $\mathrm{Rp} 4,4$ miliar terhadap kartu jaminan kesehatan atau KIS. Pada kasus ini pihak atau badan Dinas kesehatan hanya melakukan pendataan yang dimana dilakukan kerjasama dengan tingkat kecamatan dan desa untuk mendapat masyarakat yang belum terdata atau belum mendapatkan kartu jaminan kesehatan. Setelah dilakukannya pendatan dalam lingkup desa dan kecamatan maka dinas kesehatan akan menyusun anggran sebanyak berapa masayarakat yang belum terdata dan belum mendapatkan KIS tersebut. Anggran yang telah disusun oleh dinas kesehatan akan diajukan ke BKD sekaligus melakukan kerjasama dengan BAPEDA. Pada BKD dan BAPEDA akan mengkaji seberapa anggaran yang diajuakan oleh dinas kesehatan yang dimana apakah anggaran tersebut disetujui atau tidak bahkan mungkin dapat dilakukann pengurangan dalam anggaran tersebut jika terlalu besar dengan membandingkan pembiayaan dan penerimaan pada tahun sebelumnya. Dari hasil perundingan-perundingan antara BKD dan BAPEDA kesepakatan terkait pengajuan anggaran yang digunakan untuk penambahan kuota KIS yaitu disepakati tambahan kuota itu sebanyak 30 persen atau setara dengan 35.321 jiwa, dengan kebutuhan dana mencapai Rp 9,5 miliar setahun. Rinciannya APBD Provinsi sebesar Rp 5 miliar dan sisanya Rp 4,5 miliar ditanggung oleh APBD Buleleng.

\subsection{Dampak Terhadap Masyarakat Dari Anggaran Yang Belum Tereaslisasi}

Untuk diketahui, jumlah warga miskin di Buleleng yang ditanggung Pemerintah Pusat lewat KIS sebanyak 256.334 jiwa. Ternyata jumlah itu, belum semua tercover jaminan KIS. Akhirnya, warga yang tidak tercover ditanggung oleh Pemkab dan Pemprov Bali sebanyak 117.439 jiwa. Namun nyatanya, bulan Oktober 2017 kuota JKN KIS 117.439 sudah habis. Namun, permintaan KIS tinggi. Ribuan warga tercecer itu kemudian dilayani KIS PBI dengan dengan sharing APBD Provinsi dan APBD Kabupaten. Kendati yang tercecer itu sudah tertangani, ternyata masih ada yang belum terlayani. Pemkab kemudian mengusulkan pada Pemprov Bali tambahan kuota layanan KIS PBI.

Hasilnya, disepakati tambahan kuota itu sebanyak 30 persen atau setara dengan 35.321 jiwa, dengan kebutuhan dana mencapai Rp 9,5 miliar setahun. Rinciannya APBD Provinsi sebesar Rp 5 miliar dan sisanya Rp 4,5 miliar ditanggung oleh APBD Buleleng. Menariknya dana sebesar Rp 4 miliar itu belum dipasang di Anggaran Induk Dinas Kesehatan (Dinkes) Kabupaten Buleleng. Sementara Pemprov Bali sudah mengalokasikan dana sebesar Rp 5 miliar, bahkan sudah siap ditransfer. Karena kegiatan itu tidak ada dalam DIPA, sehingga dana provinsi belum dimanfaatkan. Atas belum dana tersebut menjadi penyebab belum maksimalnya realisasi pemenuhan jatah kouta KIS bagi warga Buleleng yang kurang mampu. 
Seperti berita yang kami baca, Pemerintah provinsi Bali telah mentransfer dana sebesar Rp 5 Miliar untuk realisasi penambahan kuota KIS tersebut, menariknya lagi Pemerintah kabupaten Buleleng baru berencana akan memasang sisa anggaran itu pada Anggaran Perubahan 2018 awal. Saat ini dari penambahan jatah KIS hanya bisa tercover sebesar 60 persen, dengan memanfaatkan dana transfer dari pemprov Bali sebesar Rp5 miliar. Sehingga, masih banyak masyarakat Buleleng kurang mampu yang belum tercover KIS. Sementara warga miskin dalam tambahan kuota 35.321 jiwa sudah ada yang berobat ke rumah sakit. Namun belum bisa tertangani karena dana transfer dari Pemprov Bali belum bisa di manfaatkan untuk membantu masyarakat miskin yang tercover bantuan penambahan kuota KIS.

Pemerintah berencana memasukkan di anggaran perubahan. Kami sempat mengusulkan pemerintah kabupaten menyiapkan dana cadangan untuk mengcover yang belum memiliki KIS, tapi masih diupayakan dan berharap, agar pemanfaatan jatah kuota KIS diperuntukkan bagi masyarakat miskin. Di tahun 2019 seluruh masyarakat Indonesia termasuk Buleleng sudah tercover JKN. Dari hasil verifikasi dan validasi data memang ada, jatah penambahan kouta KIS yang belum terisi. "Sekarang sudah 85 persen tercover JKN. Akan ada peningkatan hingga akhir tahun. Jika dalam perubahan anggaran, ada belum. Maka akan didukung dari ABPD Perubahan, untuk memasukan semua masyarakat ke JKN. Terus memantau pemenuhan kouta sampai dengan anggaran perubahan. Bahkan pihak pemerintah desa diminta lebih aktif mendata warganya yang kurang mampu belum tercover KIS. Pihak Desa pun harus bertanggungjawab, jika dalam pendataan itu masih ditemukan warga yang tercecer. Setiap Camat kumpulkan perbekel setiap bulan. Perbekel setiap tanggal 10 mendata, untuk pemenuhan kouta. Setiap tanggal 15, perbekel menyetor data warganya. Sudah ada mekanisme, sehingga tidak ada rekomendasi Dinsos bagi orang sakit berobat ke rumah sakit. Dan akan dipantau sampai di anggaran perubahan, jika masih belum ada, maka akan di penuhi dari ABPD Perubahan.

\subsection{Jika dana yang dialokasikan oleh Dinas Kesehatan Kabupaten Buleleng sudah terdapat dalam DIPA dan sudah terealisasi sesuai dengan APBD yang diajukan, apa langkah atau kebijakan selanjutnya?}

Untuk pemenuhan tambahan kouta itu dananya sebesar Rp9,4 miliar, dengan sistem sharing, yakni Rp5 miliar oleh Pemprov Bali dan sisanya Rp4,4 miliar oleh Pemkab Buleleng. Menariknya dana sebesar Rp4 miliar itu belum dipasang di Anggaran Induk Dinas Kesehatan (Dinkes) Kabupaten Buleleng. Atas belum dana tersebut menjadi penyebab belum maksimalnya realisasi pemenuhan jatah kouta KIS bagi warga Buleleng yang kurang mampu. Saat ini dari penambahan jatah KIS hanya bisa tercover sebesar 60 persen, dengan memanfaatkan dana transfer dari pemprov Bali sebesar Rp5 miliar. Sehingga, masih banyak masyarakat Buleleng kurang mampu yang belum tercover KIS.

Nantinya pihak Dinas Kesehatan dan Dinas Sosial akan terus memantau pemenuhan kouta sampai dengan anggaran perubahan. Bahkan pihak pemerintah desa diminta lebih aktif mendata warganya yang kurang mampu yang belum tercover KIS. Pihak Desa pun harus bertanggungjawab, jika dalam pendataan itu masih ditemukan warga yang tercecer.

Camat kumpulkan perbekel setiap bulan. Perbekel setiap tanggal 10 diminta mendata warga yang kurang mampu, sehingga nantinya tepat sasaran untuk pemenuhan kouta yang tersedia. Setiap tanggal 15, perbekel juga diharuskan agar menyetor data warga yang kurang mampu, sehingga nantinya KIS tersebut tepat sasaran untuk orang kurang mampu bukannya malah warga yang ketercukupan ekonomi yang mendapat KIS sehingga tujuan dari KIS ini tidak tercapai.

Bahwa untuk tahun 2018 dan seterusnya, Dinsos Buleleng tidak lagi secara langsung merekomendasikan KIS kepada masyarakat. dalam basis data terpadu (BDT) berasal dari data pemerintah pusat, tercantum nama warga penerima KIS di masing-masing desa/kelurahan di Buleleng. Jadi, prosedur pengusulan KIS warga masih tercecer di 148 desa dan kelurahan tidak lagi melalui Dinsos, cukup mendaftar di masing-masing desa berdasarkan form 34 dengan memetik data BDT, Selanjutnya, data warga tercecer diinput 
dari desa dan kelurahan, dikirim melalui form 34 kepada Dinsos Buleleng. Ketika data dari form 34 telah diterima, akan dilakukan cross chek dulu, apakah benar calon penerima KIS tersebut sesuai dengan 11 kriteria kemiskinan? Jika lolos, baru akan diusulkan kepada pihak BPJS.

Terkait batas waktu pengusulan, sesuai regulasi pihak Dinsos menetapkan bahwa usulan pengajuan KIS dari masing-masing desa/kelurahan ditentukan paling lambat tanggal 20 tiap bulannya. Diusahakan sebelum tanggal 20, calon penerima KIS itu sudah dikirim datanya melalui form 34 dari desa kepada Dinsos, agar nantinya bisa langsung diajukan kepada BPJS. kalau nanti sudah lewat dengan tanggal yang telah ditentukan, akan diajukan pada bulan berikutnya. Proses usulan tak berhenti sampai disitu saja, data yang sudah diterima oleh BPJS akan digodok lagi bersama Dinas Kependudukan dan Catatan Sipil Kabupaten Buleleng untuk mengkompilir NIK dan Nomor KK. Biar nantinya semua sesuai dengan NIK dan KK. Jangan sampai nama orangnya lain, namun NIKnya sama, dan juga bisa terjadi orangtuanya dapat KIS, namun memiliki anak tiga tapi dua anaknya tidak mendapatkan KIS. Jika begitu yang terjadi dilapangan dimohonkan agar segera konfirmasi kepada pihak BPJS bukan kepada Dinsos lagi.

Dengan adanya penambahan kouta KIS di tahun 2018 ini sedikitnya bisa mengurangi permaslahan yang dihadapi masyarakat kurang mampu, khususnya bagi mereka yang belum mendapat pelayanan jaminan kesehatan dari pemerintah. itupun menghimbau dengan ketersediaan kuota KIS di Buleleng, dimohonkan agar seluruh perbekel/lurah agar segera melakukan pendataan dan mendaftarkan warga kurang mampu di kantor desa setempat melalui BDT. Terutama untuk warga kurang mampu yang datanya tercecer, dan memenuhi 11 kriteria kemiskinan agar segera dimasukkan form 34 dikirim ke Dinsos Buleleng.

Langkah tersebut agar pembagian KIS lebih transparan dan tepat sasaran. Jangan sampai nanti masih ada warga kurang mampu yang tercecer, padahal tambahan kuota ini melebihi jumlah warga yang mesti ditanggung sesuai BDT. KIS ini harus dimanfaatkan dengan sebaik-baiknya. Sehingga KIS dibagikan tepat kepada warga yang membutuhkan. upaya itu dapat dilakukan dengan cara membuka data penerima yang ada dalam BDT. Dengan data dibuka, semua warga mengetahui, apakah dirinya tercatat atau tidak. Dan bisa memberi penjelasan bagi warga, kalau memang tidak tercatat agar diharapkan untuk mengurusnya, jika memang warga kurang mampu.

Dengan dibukanya data, verifikasi data juga dapat dilakukan. Karena mungkin saja, ternyata ada warga yang tercatat, tetapi sudah meninggal, sehingga jatahnya bisa dialihkan kepada warga yang memang layak diberikan. Kalau bisa agar data-data tersebut ditempel di kantor desa, sehingga warga yang ingin memproleh KIS, bisa melihat data tersebut. Dan aparat desa nanti bisa menindaklanjuti data itu dengan mengajukan usulan kepada Dinas Sosial. Dalam pelaksanaannya, warga yang kurang mampu yang berhak mendapat tanggungan KIS adalah mereka yang diusulkan oleh desa/kelurahan, kepada Dinas Sosial. Selanjutnya, Dinas Sosial kemudian melanjutkan ke BPJS untuk dicetakkan KIS. Dalam ketentuannya, sejatinya warga kurang mampu yang dapat diusulkan mendapat KIS oleh pihak desa/kelurahan adalah mereka yang tercatat dalam BDT.

\section{Simpulan dan Saran}

Kartu Indonesia Sehat (KIS) adalah kartu yang dimana memberikan Jaminan Kesehatan yang sekaligus menjadi kartu identitas bagai pemegang kartu tersebut. Dalam KIS tersebut dikelola oleh Badan Penyelenggara Jaminan Sosial (BPJS) yang diberikan kepada penduduk Indonesia Khususnya fakir miskin dan tidak mampu serta iurannya dibayarkan oleh pemerintah.

Pada kasus yang diambil mengenai penggaran KIS sebesar yang dimana tidak terealisasi, yang dimana dalam proses penggaran dana KIS tersebut akan mengalami beberapa tahapan proses yang akan dilakukan dimulai dari penyusunan anggaran oleh dinas kesehatan yang bekerjasama dengan dinas social yang sekaligus dengan kecamatan dan kator lurah untuk proses pendataan, setelah terdata akan dilakukan prose pengajuan anggran ke BAPEDA dan BKD untuk tahap pengkajian apakah pengganggaran tersebut bisa 
diajukan datau disetujui atau sebalikanya. Jika penganggran yang dilakukan oelh dinas kesehatan sudah diterima maka, dalam realisasi KIS terhadap masyarakat khususnya pada Kabupaten Buleleng dapat dilangsungkan.

Selain itu pada masyarakat yang sudah terdata namun telah meninggal Kartu Indonesia Sehat (KIS) dapat dialihkan kepada masyarakat yang kurang mampu dan tentunya akan membutuhkan kerjasama dari masyarakat atau individu (Pihak Keluarga) itu sendiri untuk ikut bekerjasama aktif dalam mengkonfirmasi kepada Kantor Kepala Desa atau Lurah/Kantor Kecamatan untuk proses pengalihan KIS.

Saran yang dapat penulis berikan yaitu diharapkan dalam pengajuan anggaran untuk realisasi kuota Kartu Indonesia Sehat (KIS) untuk masyarakar di Kabupaten Buleleng bisa lebih dikaji bersama antara pihak-pihak yang terkait agar anggaran yang sudah disetujui tersebut dapat terealisasi sepenuhnya. Selain itu pengawasan dalam hal pengelolaan anggaran untuk penambahan kuota KIS agar terus dilakukan agar mencegah terjadinya penyelewengan terhadap anggaran yang digunakan. Segala bentuk realisasi dari perencanaan anggaran penambahan kuota KIS dapat di sosialisasikan atau dikomunikasikan kepada Pemkab Buleleng dan khususnya masyarakat di Kabupaten Buleleng agar nantinya masyarakat mengetahui hal-hal yang mengenai adanya tambahan kuota KIS dan dapat segera mendaftar diri kepada Kepala Desa setempat untuk bisa segera mendapatkan kartu Indonesia pintar (KIS). Sehingga dapat meningkatkan pemerataan kesejahteraan masyarakat di Kabupaten Buleleng.

\section{DAFTAR PUSTAKA}

Anonim. 2015. Kartu Indonesia Sehat: Pengertian dan Manfaat yang Diberikan. Tersedia di https://cermati.com/artikel/kartu-indonesia-sehat-pengertian-dan-manfaat-yangdiberikan. Diakses pada tanggal 10 April 2018.

Berita Dewata. 2018. "Kuota Realisasi KIS di Buleleng belum Maksimal". Tersedia di https://beritadewata.com/kuota-realisasi-kis-di-buleleng-belum-maksimal/. Diakses pada tanggal 13 Juni 2018.

Dinas Kesehatan Kabupaten Buleleng. Tersedia di https://dinkes.bulelengkab.go.id/. Diakses pada tanggal 13 Juni 2018.

Herawan, Kadek Edi.2018. Wawancara Anggaran KIS di Dinas Kesehatan Kabupaten Buleleng.

Ulum, Dr. Ihyaul, Hafies Sofyani. 2016. Akuntansi (Sektor) Publik. Malang: Aditya Media Publishing. 